\section{Bilateral pterygium in the two siblings}

\author{
Suleyman Ciftci, ${ }^{1}$ Leyla Ciftci $^{2}$ \\ 'Department of Ophthalmology, \\ Diyarbakir Training and Research \\ Hospital; ${ }^{2}$ Department of Cardiology, \\ Faculty of Medicine, Dicle University, \\ Diyarbakir, Turkey
}

\begin{abstract}
Pterygia are fibrovascular connective tissue overgrowths of bulbar conjunctiva onto the cornea. There is a worldwide distribution of pterygium, but it occurs more commonly in warm, dry climates. Patients younger than the age of 15 rarely acquire a pterygium. We report a case of bilateral nasal pterygium in two siblings. A 10-year-old boy and a 12-year-old girl who are siblings presented with bilateral nasal pterygium. While pterygium is a common disorder, its bilaterality in young people is not a common condition. This report is the first known report in the peer-reviewed medical literature of patients with bilateral nasal pterygium in siblings younger than the age of 15.
\end{abstract}

\section{Introduction}

Pterygia are fibrovascular connective tissue overgrowths of bulbar conjunctiva onto the cornea. They are horizontally located in the interpalpebral fissure on either the nasal or temporal side of the cornea. Histopathologic examination reveals that the subepithelial tissue exhibits elastotic degeneration of collagen, resulting from breakdown of the collagen and destruction of Bowman's membrane. Patients younger than the age of 15 rarely acquire a pterygium. ${ }^{1}$

\section{Case Report}

A 10-year-old boy and a 12-year-old girl who are siblings presented with bilateral nasal pterygium. On examination, the anterior segments in both eyes of both patients were otherwise normal, as were the posterior segments as well as the intraocular pressures (Figures 1 and 2). The visual acuity of the boy was $8 / 10$ in the right eye and 9/10 in the left eye without correction. The visual acuity of the girl was $9 / 10$ in each eye without correction. There was no evidence of other functional impairments in either of the two siblings. None of their par- ents or their first-degree relatives, who live under the same environmental and geographical conditions, had any pterygia.

\section{Discussion}

There is a worldwide distribution of pterygium, but it is more common in warm, dry climates. The association between ultraviolet radiation and formation of pterygia is strong. In addition, local drying of the cornea and conjunctiva in the interpalpebral fissure from tear film abnormalities may lead to fibroblastic growth. ${ }^{1}$ There is also some evidence that hereditary factors play a role in the development of pterygium. Several case reports suggest a possible autosomal dominant pattern of occurrence. ${ }^{2-4}$ Our knowledge of the pathogenesis of pterygium has increased in recent years. Recently, Jaworski et al. ${ }^{5}$ studied some of the genes that play a role in cell migration. These gene products include spermidine/spermine N1-acetyltransferase 1, clusterin, S100 protein, and keratins. Among migration-related genes present in pterygia is the gene SAT1, which encodes for the enzyme spermidine/ spermine N1-acetyltransferase 1. SAT1 is abundant particularly at the body of the pterygium. One polyamine analogue, IPENSpm, a potential inhibitor of SAT1, significantly reduces migration in primary cultures of pterygium. ${ }^{5}$ Another of the more abundantly expressed gene products in pterygia is clusterin. Clusterin has many functions and is known by several synonyms: apolipoprotein $\mathrm{J}$, testosterone-repressed prostate message 2, sulfated glycoprotein 2, and complement-associated protein SP-40. Clusterin is abundant
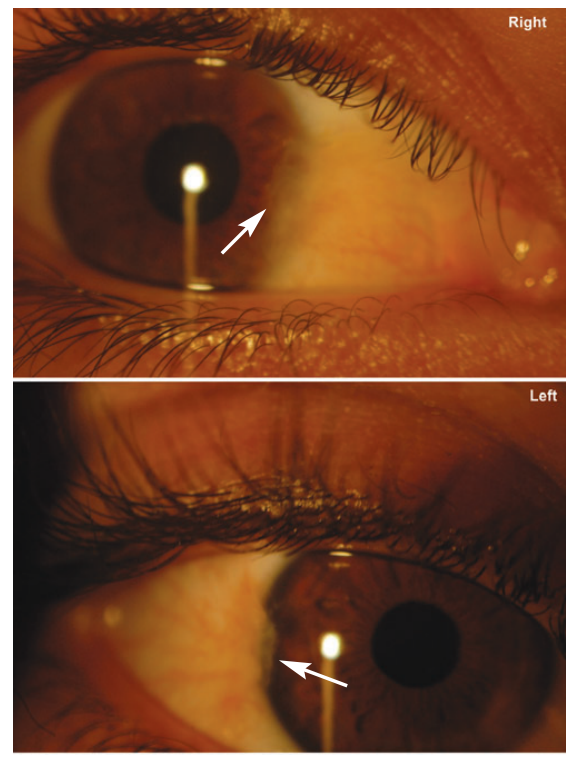

Figure 1. Nasal pterygia (arrows) in the right and left eyes of the 10-year-old boy.
Correspondence: Suleyman Ciftci, Diyarbakir Eğitim ve Araştirma Hastanesi Göz Hastalikları Polikliniği, 21000 Diyarbakir, Turkey.

Tel: +90.412.2570206 - Fax: +90.0412.2245267.

E-mail: ciftci1977@hotmail.com

Key words: bilaterality, pterygium, sibling, young patients.

Conflict of interest: the authors report no conflicts of interest.

Received for publication: 6 April 2011. Accepted for publication: 30 May 2011.

This work is licensed under a Creative Commons Attribution NonCommercial 3.0 License (CC BYNC 3.0).

(C) Copyright S. Ciftci and L. Ciftci, 2011

Licensee PAGEPress, Italy

Eye Reports 2011; 1:e1

doi:10.4081/eye.2011.e1

particularly at the fibrovascular body of the pterygium. ${ }^{5}$

S100 proteins comprise a multitude of low molecular weight, calcium-binding proteins that interact with other proteins to modulate biological processes. ${ }^{6,7}$ S100A8 and S100A9 are present at higher levels in pterygia than in uninvolved conjunctiva, and present in tear fluids of patients with pterygia. S100A9 (also known as calgranulin B) is abundant particularly at the leading edge of the pterygium body. S100A9 may be a pterygium and/or conjunctiva marker $^{5,6}$ and may also serve as an especially useful indicator for predicting recurrent pterygium. ${ }^{8}$ Kerkhoff et al. have showed that S100A8 and S100A9 are released from neutrophils by a
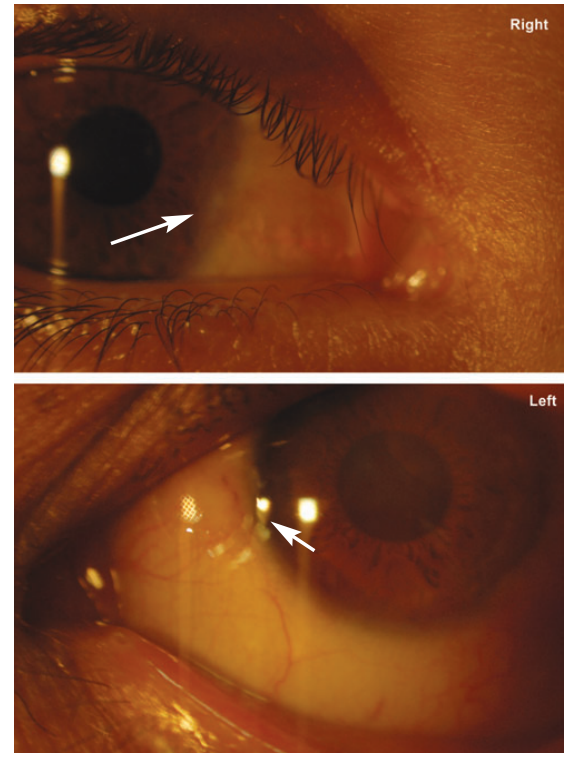

Figure 2. Nasal pterygia (arrows) in the right and left eyes of the 12-year-old girl. 
microtubule-dependent mechanism and may induce inflammation by influencing leukocyte trafficking. ${ }^{9}$

Jaworski et al. suggested the hypothesis that a pterygium may spread across the corneal surface by migration of cells bearing conjunctival and limbal markers into the corneal epithelium. ${ }^{5}$ They observed migration-related transcripts of the following proteins: keratin 19, found in limbal stem cells; keratins 4 and 13 , found in conjunctiva and limbal cells; and aldehyde dehydrogenase, found in corneal epithelial cells. $^{5}$

Matrix metalloproteinases (MMPs) also play a role in the development of pterygium. The pterygial cells which invade over Bowman's layer were found to have produced increased matrix metalloproteinases. MMP-1, MMP-2, and MMP-9 are likely the main MMPs responsible for dissolution of Bowman's layer, by activating fibroblasts at the head of the pterygium, nearest to intact Bowman's layer. ${ }^{10}$ The finding of increased MMPs at the leading edge of a pterygium led to a more recent study on the effect of doxycycline, an MMP inhibitor on pterygium growth. Doxycycline was shown to reduce migration of pterygial epithelial cells in culture. ${ }^{11}$

Tong et al. concluded that aberrant wound healing processes play a role in pterygium pathogenesis. They compared expression of primary pterygia, recurrent pterygia, and uninvolved conjunctiva, and observed increased expression of adhesion molecules and extracellular matrix and structural proteins (fibronectin; collagen and keratin family members). Expression of epithelial-mesenchymal transition (EMT), with down-regulation of Ecadherin and up-regulation of $\beta$-catenin and lymphoid-enhancer-factor-1, has also been proposed as a mechanism for the origin of pterygial fibroblasts. ${ }^{16}$

Vascular endothelial growth factor (VEGF) plays an important role in fibrovascular component of pterygia. Recently Tsai et al. evaluated potential associations between pterygium formation and the VEGF gene- 460 polymorphism. They observed no significant differences seen between pterygium and control groups in age and sex, but found that VEGF-460C polymorphism is associated with pterygium formation in young female patients. ${ }^{17}$

Dushku and Reid found that there is increased expression of p53 in all pterygia they studied. The increased amount of p53 protein in pterygial cells does not cause apoptosis or block cell proliferation, suggesting that the normal p53 functions are inactivated in pterygia. ${ }^{10}$ Despite the increased amount of p53 protein in pterygial cells, pterygium has been described by some as a benign neoplastic lesion. ${ }^{13-15}$

Conversely, the small leucine-rich proteoglycan (SLRP) family is highly expressed in the cornea and is believed to contribute to corneal transparency. Members of this family include decorin, keratocan, lumican, and mimecan (also called osteoglycin). SLRPs are collectively down-regulated in pterygium. Furthermore, there are no transcripts for any of these SLRPs in the pterygium library. ${ }^{5,12}$

\section{Conclusions}

Pterygium is a common disorder; however, it is not common in childhood. ${ }^{4}$ Few cases of pterygia in childhood have been reported. In a series of 95 patients with pterygia, Ajayi and Bekibele $^{18}$ reported the youngest was a 10 year-old child with a pterygium. Islam and Wagoner ${ }^{2}$ reported a family with pterygia. One member of the family was a 4-year-old child. Belliveau and $\mathrm{Ali}^{19}$ reported a 3 -year-old child with a pterygium due to xeroderma pigmentosum; pterygia are a common finding in xeroderma pigmentosa. In the cases in children reported, all except one patient, which reported by Islam and Wagoner, were unilateral. In none of the cases reported was there a history of a sibling with a pterygium. Our case is unique in that it is a sibling pair with pterygia, that are also bilateral. I have previously reported a boy with bilateral nasal pterygium..$^{20}$ This report is the first known report in the peerreviewed medical literature of patients with bilateral nasal pterygium in siblings younger than the age of 15.

\section{References}

1. Stephen G. Waller, Anthony P. Adamis. Pterygium. Chapter 35. In: William Tasman, eds. Duane's Clinical Ophthalmology on CD-ROM. 1st ed. Philadelphia: Lippincott Williams \& Wilkins, 2006.

2. Islam SI, Wagoner MD. Pterygium in young members of one family. Cornea 2001;20:708-10.

3. Zhang JD. An investigation of aetiology and heredity of pterygium. Report of 11 cases in a family. Acta Ophthalmol 1987;65:413-6.

4. Saw SM, Tan D. Pterygium: prevalence, demography and risk factors. Ophthalmic Epidemiol 1999;6:219-28.

5. Jaworski CJ, Aryankalayil-John M, Campos MM, et al. Expression analysis of human pterygium shows a predominance of conjunctival and limbal markers and genes associated with cell migration. Mol Vis 2009;15:2421-34.

6. Riau AK, Wong TT, Beuerman RW, Tong L. Calcium-binding S100 protein expression in pterygium. Mol Vis 2009;15:335-42.

7. Tu CL, Chang W, Bikle DD. The extracellular calcium-sensing receptor is required for calcium-induced differentiation in human keratinocytes. J Biol Chem 2001;276:41079-85.

8 Zhou L, Beuerman RW, Ang LP, et al. Elevation of human alpha-defensins and S100 calcium-binding proteins A8 and A9 in tear fluid of patients with pterygium. Invest Ophthalmol Vis Sci 2009;50:207786.

9. Kerkhoff C, Klempt M, Kaever V, Sorg C. The two calcium-binding proteins, S100A8 and S100A9, are involved in the metabolism of arachidonic acid in human neutrophils. J Biol Chem 1999;274:32672-9.

10. Reid TW, Dushku N. What a study of pterygia teaches us about the cornea? Molecular mechanisms of formation. Eye Contact Lens 2010;36:290-5.

11. Cox CA, Amaral J, Salloum R, et al. Doxycycline's effect on ocular angiogenesis: an in vivo analysis. Ophthalmology 2010;117:1782-91.

12. Kao WW, Liu CY. Roles of lumican and keratocan on corneal transparency. Glycoconj J 2002;19:275-85.

13. Dushku N, Reid TW. Immunohistochemical evidence that human pterygia originate from an invasion of vimentinexpressing altered limbal epithelial basal cells. Curr Eye Res 1994;13:473-81.

14. Weinstein 0, Rosenthal G, Zirkin H, et al. Overexpression of p53 tumor suppressor gene in pterygia. Eye 2002;16:619-21.

15. Tan DT, Tang WY, Liu YP, et al. Apoptosis and apoptosis related gene expression in normal conjunctiva and pterygium. Br J Ophthalmol 2000;84:212-6.

16. Tong L, Chew J, Yang H, et al. Distinct gene subsets in pterygia formation and recurrence: dissecting complex biological phenomenon using genome wide expression data. BMC Med Genomics 2009;2:14.

17. Tsai YY, Chiang CC, Bau DT, et al. Vascular endothelial growth factor gene 460 polymorphism is associated with pterygium formation in female patients. Cornea 2008;27:476-9.

18. Ajayi BG, Bekibele CO. Evaluation of the effectiveness of post-operative beta-irradiation in the management of pterygium. Afr J Med Med Sci 2002;31:9-11.

19. Belliveau MJ, Ali A. Pterygium resection with conjunctival autograft in a young child with xeroderma pigmentosum. Cornea 2008;27:1174-5.

20. Ciftci S. Bilateral pterygium, symmetrical nodosity of the auricle, and free iris cyst. Can J Ophthalmol 2009;44:713. 